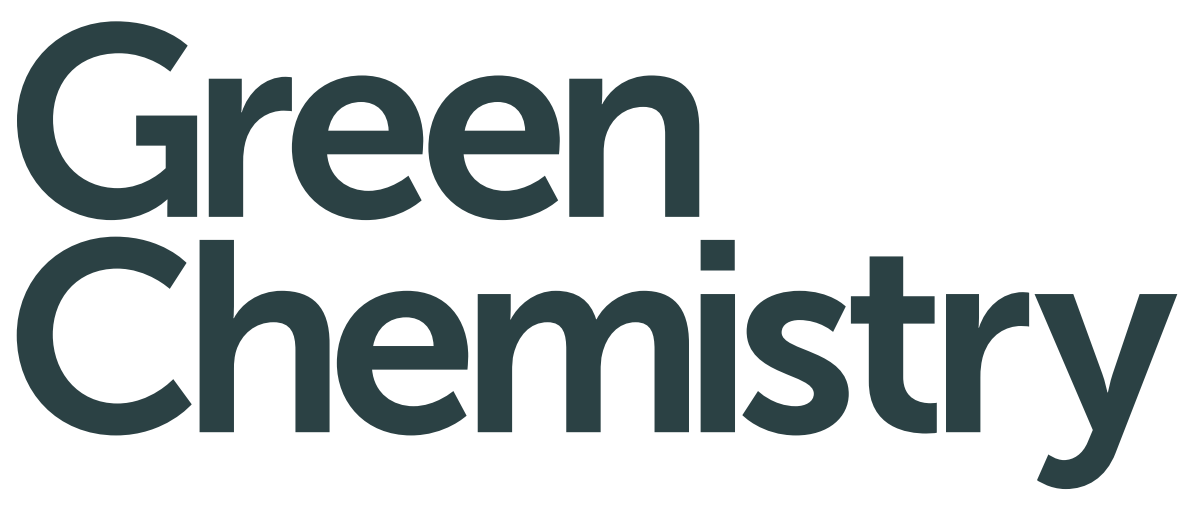

Accepted Manuscript

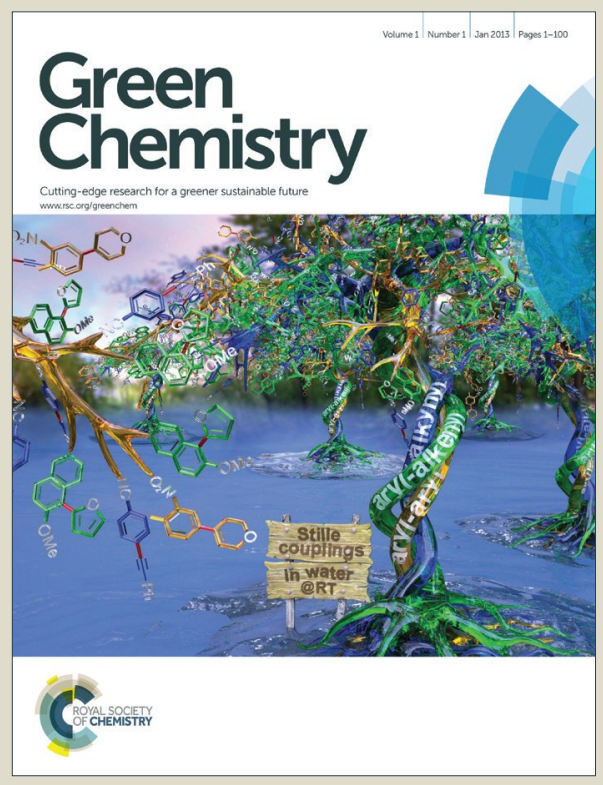

This is an Accepted Manuscript, which has been through the Royal Society of Chemistry peer review process and has been accepted for publication.

Accepted Manuscripts are published online shortly after acceptance, before technical editing, formatting and proof reading. Using this free service, authors can make their results available to the community, in citable form, before we publish the edited article. We will replace this Accepted Manuscript with the edited and formatted Advance Article as soon as it is available.

You can find more information about Accepted Manuscripts in the Information for Authors.

Please note that technical editing may introduce minor changes to the text and/or graphics, which may alter content. The journal's standard Terms \& Conditions and the Ethical guidelines still apply. In no event shall the Royal Society of Chemistry be held responsible for any errors or omissions in this Accepted Manuscript or any consequences arising from the use of any information it contains. 


\title{
Simulation and Life Cycle Assessment of Algae Gasification Process in Dual Fluidized Bed Gasifiers
}

\author{
Pooya Azadi, ${ }^{a}$, George Brownbridge, ${ }^{a}$ Sebastian Mosbach, ${ }^{a}$ Oliver Inderwildi, ${ }^{b}$ and Markus Kraft*a
}

\author{
Received Xth XXXXXXXXXX 20XX, Accepted Xth XXXXXXXXX 20XX \\ First published on the web Xth $X X X X X X X X X X 200 X$ \\ DOI: 10.1039/b000000x
}

We present simulation results for the production of algae-derived syngas using dual fluidized bed (DFB) gasifiers. A global sensitivity analysis was performed to determine the impact of key input parameters (i.e. algae composition, gasification temperature, feed water content, steam-to-biomass ratio, and fuel-air equivalence ratio) on the product yields. The algae oil content was varied from 0 to $40 \mathrm{wt} \%$ to account for different algae strains and varying extents of oil extraction prior to the gasification process. It was found that the lower heating value (LHV) of syngas, typically ranging from 15 to $22 \mathrm{MJ} / \mathrm{kg}_{\text {algae }}$, is heavily dependent to the algae oil content. The cold gas efficiency (CGE) of the process varies over a range of 75 to $90 \%$, depending primarily on the feedstock water content and steam-to-biomass ratio. A cradle-to-grave life cycle assessment indicated that the carbon footprint of syngas produced from algae feedstocks with 20 to $40 \mathrm{wt} \%$ oil fraction that is dried by a gas-fired dryer lies within a range of 70 to $195 \mathrm{~g} \mathrm{CO}_{2} / \mathrm{MJ}$. However, decarbonization of the drying stage via utilization of solar energy reduce the carbon footprint to values below $40 \mathrm{~g} \mathrm{CO}_{2} / \mathrm{MJ}$, which would compare favorably with the carbon footprint of syngas produced via steam reforming of natural gas (i.e. $\sim 100 \mathrm{~g} \mathrm{CO}_{2} / \mathrm{MJ}$ ).

\section{Introduction}

\begin{tabular}{ll} 
Nomenclature & \\
\hline CGE & Cold Gas Efficiency \\
FAER & Fuel-Air Equivalence Ratio \\
GHG & Greenhouse Gas \\
GWP & Global Warming Potential \\
HDMR & High Dimensional Model Representation \\
HX & Heat Exchanger \\
HXTA & Heat Exchanger Temperature Approach \\
LCA & Life Cycle Assessment \\
LHV & Lower Heating Value \\
OEA & Oil-Extracted Algae \\
Syngas & Synthesis Gas \\
$\mathrm{T}_{c}$ & Temperature of Combustor \\
$\mathrm{T}_{r}$ & Temperature of Reformer \\
VM & Volatile Matter \\
\hline
\end{tabular}

Generally, thermochemical pathways for the conversion of biomass pursue one of the following two strategies to address the challenges caused by the presence of different fractions -

${ }^{a}$ Department of Chemical Engineering and Biotechnology, University of Cambridge, New Museums Site, Pembroke Street, Cambridge, CB2 3RA, United Kingdom.E-mail:mk306@cam.ac.uk

${ }^{b}$ World Economic Forum, 91-93 route de la Capite, Geneva, CH-1223 Cologny, Switzerland. and thus vastly different chemical structures — within a parent biomass feedstock: i) focusing on direct conversion of, at least, one of the fractions to molecules with a similar carbon number and chemical structure to that of the desired product via fractionation and/or partial decomposition; ii) ultimate decomposition of the whole feedstock to form gaseous products such as syngas and methane which, if desired, can be further processed to produce hydrogen and synthetic liquid fuels. The biomass conversion pathways based on the former strategy allow for the direct production of liquid hydrocarbons (e.g. $\mathrm{C}_{5}-$ $\mathrm{C}_{20}$ ) from targeted fractions at high selectivity ${ }^{1}$ but typically produce a large quantity of byproducts from the other fractions. If fractionation is carried out using a chemical method, the byproducts - i.e. solid residues - often have a more condensed structure than their parent molecules in the feedstock ${ }^{2}$ and therefore are more difficult to process further (e.g. solid char produced as a byproduct of acid hydrolysis of lignocellulosic biomass). In contrast, processing the biomass by following the latter strategy (i.e. ultimate decomposition) results in the formation of $\mathrm{C}_{1}$ gases (i.e. carbon monoxide, methane) in high yields. However, owing to their low economic value, these gases should be catalytically valorized to form highvalue products (e.g. hydrogen, methanol, liquid biofuels), or be used on-site to generate heat and power.

The conversion pathways for the production of algal biofuels based on the abovementioned strategies are illustrated in Figure 1. Although the separation of algae oil from a dry feedstock and its subsequent conversion to biodiesel can be 
achieved at high yields, the drying of dilute algae cultures prior to the extraction process is a major barrier preventing an economic and environmentally-benign realization of its potential. Several alternative methods have been suggested to overcome this barrier, among which wet extraction, liquefaction, and solar drying have shown great promise. In particular, the use of solar drying would pave the way for the implementation of some of the most viable and mature technologies for the processing of biomass, namely solvent extraction of the lipid and air/steam gasification. However, despite its apparent simplicity, there are some practical obstacles that hold back the use solar energy to remove large quantities of water from dilute algae slurries. Firstly, continuous operation of the biorefinery would greatly depend on the climate upon using solarpowered dryers. Moreover, the long period of time needed to dry algae using solar energy not only increases the land area occupied by algal biorefineries but also substantially increases the vulnerability of the algae oil to degradation. The latter issue is of great importance when the dried feedstock will be used for biodiesel production, but it will have a less pronounced impact if algae is converted to syngas as gasification is less sensitive to the exact chemical composition of the feedstock. Considering the above issues, one may think that a hybrid strategy in which algae oil is extracted using wet oil extraction processes for biodiesel production while the oilextracted algae is dried by solar energy and subsequently converted to syngas would represent a viable scenario for algal biorefineries ${ }^{3}$.

In spite of extensive studies into different aspects of algal biofuels over the past decade ${ }^{4}$, the conversion of microalgae feedstock to syngas and hydrogen via thermochemical routes has received very little attention thus far. Recently, a few studies have reported the gasification of microalgae feedstock in fluidized bed reactors with and without co-feeding of other solid fuels ${ }^{5,6}$. These preliminary studies into the production of algae-derived syngas have been promising, although some technical issues relating to the high ash content of the feed were encountered. A recent thermogravimetric study has revealed that the algae char can be converted at a rate of 2.5 $\mathrm{wt} \% / \mathrm{min}$ at $850^{\circ} \mathrm{C}$ with a steam concentration of $5 \mathrm{vol} . \%^{7}$. Beside conventional gasification - which can only handle dried biomass - an alternative gasification process in supercritical water medium is under development in which algae feed with low solid contents (e.g. $<20 \mathrm{wt} \%$ ) can be converted into gas mixtures containing methane, hydrogen, and carbon dioxide $^{8-11}$. Due to the elimination of the drying step, utilization of this process can substantially reduce the energyintensity of the conversion process and in turn, enhance the environmental benefits. Nevertheless, the catalytic supercritical water gasification process, and in particular, its implementation for the conversion of ash-containing feedstocks such as algae has not yet reached the same level of technology-readiness as have conventional gasification configurations. Provided that the issues regarding the separation of ash are resolved, the catalytic supercritical water gasification process presents an ideal choice for the production of combustible gases from both fresh and oil-extracted algae slurries which can be byproducts of the wet oil extraction and liquefaction processes.

While it is generally accepted that the conversion of biomass to biofuel can be part on an overall solution to the issue of fossil resource depletion, the impact of large-scale biofuel production on the environment, and in particular, their potential to reduce our greenhouse gas (GHG) emissions, is not thoroughly understood. Hence, one can expect that insights into the latter matter would have a profound and farreaching implications on shaping the future governmental incentives towards biofuels which would, in turn, greatly affect their widespread production. As such, life cycle assessment (LCA) has become an important line of research within the biofuel arena. As far as algal biofuels are concerned, a life cycle assessment should include GHG emissions associated with the production of fertilisers and plant construction materials, on-site consumption of heat and electricity, and transportation of commodities and materials. Since algae ponds can be built in arid or semi-arid lands, the emissions due to land-use change can be omitted from the analysis. The life cycle carbon footprint and fossil energy consumption of algae-derived biodiesel have been rigorously studied and reported in the literature $^{12-14}$. These studies have revealed that the life cycle GHG emissions from algal biodiesel are heavily dependent on the carbon intensity of the methods that are implemented for drying and oil extraction, as well as the strategy upon which the oil-extracted algae is utilized. One would expect that certain parts of these studies, such as the analysis of the GHG emission associated with algae cultivation and dewatering, are also applicable to the LCA of algal syngas production.

Due to its relatively high technology readiness level, the conversion of algae to syngas and hydrogen via gasification offers a promising route for the realization of algal energy in the near-term future, which would in turn allow for the development of industrial scale algae cultivation and processing infrastructure. Herein, we present the results obtained from the simulation of the algae gasification process in a dual fluidized bed biomass gasifier. We will then discuss how the key input parameters (i.e. algae oil content, feedstock moisture, gasifier temperature, and steam-to-carbon and air-to-carbon ratios) can affect the product yields and cold gas efficiency. Finally, we determine the life cycle GHG emissions of syngas production from the gasification of algae feedstock where the focus is devoted to the effects of the feedstock drying method and algae oil content. 


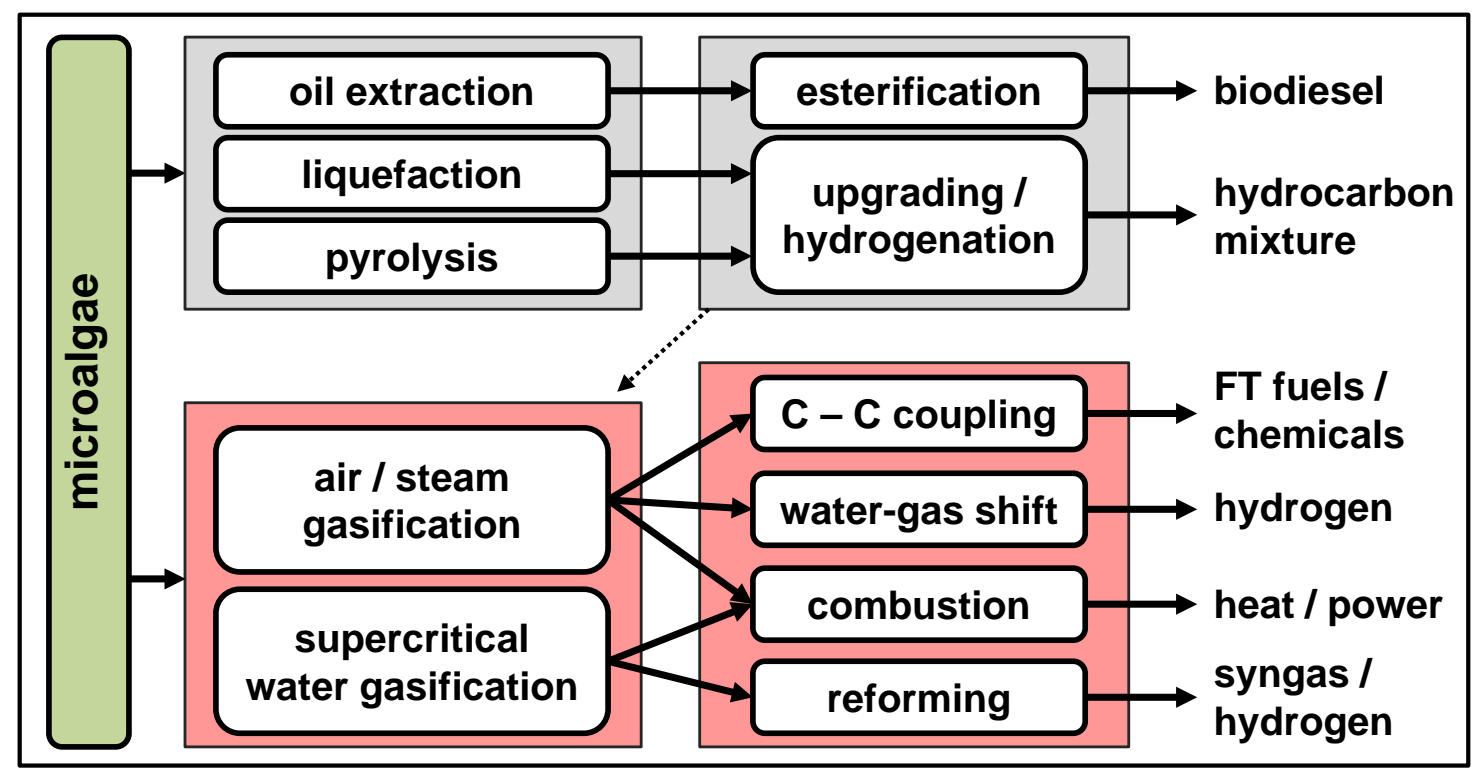

Fig. 1 Strategies for the production of algal biofuels based on fractionation/depolymerization (i.e. oil extraction, liquefaction, and pyrolysis) and decomposition to $\mathrm{C}_{1}$ molecules (i.e. gasification).

\section{Methodology}

\subsection{Algae Gasification Process}

The process flow diagram of the algae gasification plant considered in this study is shown in Figure 2. The simulation was carried out using the Aspen Plus ${ }^{\circledR}$ process simulation package. The Peng-Robinson equation of state was used throughout this study both for thermal calculations and for Gibbs energy minimization. The overall chemical reactions that occur in the gasification reactor was simulated using a yield-based unit for the pyrolysis reactions and an equilibrium-based for the reforming reactions. The role of the pyrolyzer was to split the feed into volatile matter (VM) and char, the former of which was fed to the reformer and the latter one to the combustor. The value of fuel-air equivalence ratio (FAER) was adjusted in each simulation based upon the char and syngas flow rates to the combustor. The elemental composition of VM was calculated by subtracting the desired amount of char (i.e. carbon) from the microalgae feedstock. The combustor, also an equilibrium based reactor, had three inputs (char, air, and auxiliary syngas fuel) and two outputs (flue gas and ash).The temperature of the combustor was set to be $150^{\circ} \mathrm{C}$ higher than that of the reformer in that simulation. The heat transfer between the combustor and reformer was simulated using an energy stream and the circulation of the bed material between the two reactors was neglected for simplification. A summary of the design specifications and other information relating to each block is provided in Table 1. It is worth mentioning that the product distribution in a yield-based reactor is specified by the user, which in the case of pyrolyzer is the percentage of carbon that contributes towards the formation of char. In contrast, in equilibrium-based reactors that were used for the reformer and combustor the product distribution is dependent on the operating conditions, the elemental composition of the feed, and the allowable products (as listed in Table 1). The heat exchanger network was arranged such that the outlet temperatures of the syngas and flue gas were both $120^{\circ} \mathrm{C}$ and the temperature difference between the two streams never goes below $20^{\circ} \mathrm{C}$. The reader is referred to reference ${ }^{15}$ for more information on practical aspects of fluidized bed gasifiers.

A total of 2000 simulations obtained by varying five input parameters. The results of these simulations were used to generate surrogate models which were in turn utilized to perform the global sensitivity analysis as explained in the next subsection. The input parameters included algae oil content, feedstock moisture content, gasifier temperature, steam to biomass ratio, and fuel-air equivalence ratio. The ranges considered for the key input parameter values are given in Table 2. The elemental compositions and lower heating values (LHV) of the algae fractions were taken from reference ${ }^{4}$ and are listed in Table 3. The elemental composition and LHV of these fractions, in turn, were used to calculate the overall elemental composition of the different algae feedstocks and their corresponding heating values (Table 4) based on the rule of mixtures. The algae feeds in the simulations were defined as an unconventional solids based on their elemental compositions. 
For each of these four algae compositions, 500 simulations were automatically run by Aspen Plus by varying the other four parameters on a specified grid. The reader is referred to references ${ }^{16-19}$ for other examples of the use of Aspen Plus ${ }^{\circledR}$ for the simulation of the biomass gasification process.

All values reported in this study are, unless otherwise stated, based on one kilogram of dry algae. The cold gas efficiency (CGE) was defined as the ratio between the sum of the energy content of all of the products to that of the feed. We note that the energy content of the produced ammonia was included in the calculation of CGE but was excluded from the calculations of the LHV of syngas.

\subsection{Global Sensitivity Analysis}

The global sensitivities of the LHV, CGE, and gas yields for the described process were calculated using a High Dimensional Model Representation (HDMR) method in which the whole space of the input variables, as listed in Table 2, is considered when calculating the sensitivities. This means that the magnitude of the range over which each parameter is allowed to vary has a direct impact on the sensitivity to that parameter. Such analysis not only makes it possible to cope with the inherent uncertainties in the input parameters but also accounts for the potential non-linearities and contributions due to interactions between input parameters. A full factorial experiment design consisting of a total of 2000 model evaluations was implemented to calculate global sensitivities and generate surrogate models. The same method has been previously applied to analyse the economic viability of algal biodiesel under technical and economic uncertainties ${ }^{20}$ and to determine the environmental impact of algae-derived biodiesel ${ }^{12}$. Although in the present work surrogate models are constructed only for the purpose of global sensitivity analysis, they can potentially be a very powerful tool for the optimization of such complex processes with several internal setpoints, optimization subroutines, and recycle streams. One is referred to ${ }^{21}$ for further information regarding the development of the HDMR method.

\subsection{Life Cycle Assessment}

The GHG emissions associated with the production of algae in open pond raceways and the subsequent steps to reach a slurry with $20 \mathrm{wt} \%$ solid content have been taken from our previous article ${ }^{12}$. The following assumptions were made in the analysis presented here: plant lifetime of 30 years, biomass annual productivity of 80 tonne/ha on a dry basis, pond water velocity of $0.25 \mathrm{~m} / \mathrm{s}$, and fertiliser loss of $7.5 \%$ of the applied rate. It was also assumed that the solid concentration of the produced algae is $0.5 \mathrm{~kg} / \mathrm{m}^{3}$ which is increased to $50 \mathrm{~kg} / \mathrm{m}^{3}$ using two consecutive clarifiers and then to $20 \mathrm{wt} \%$ using a centrifuge with a specific power consumption of $3.6 \mathrm{MJ} / \mathrm{m}^{3}$. The solid content of the feed was then increased to $70 \mathrm{wt} \%$ using one of the three scenarios outlined below.

In the first scenario, a conventional biomass belt dryer powered by the heat and electricity generated from the on-site combustion of syngas was considered. The specific heat and electricity consumption of the dryer was assumed to be 3.5 and $0.37 \mathrm{MJ}$ per kilogram of removed water, respectively ${ }^{22}$. In the second scenario, it was assumed that the concentration of the algae slurry is first increased to $30 \mathrm{wt} \%$ by solar energy before being fed to the belt dryer. The last scenario represents a case where the solid content of algae slurry is increased to $70 \mathrm{wt} \%$ solely by the use of solar energy.

The gasification plant was assumed to operate at the nominal process values given in Table 2 while the algae oil content was varied between 20 to $40 \mathrm{wt} \%$ (on a dry basis). The use of algae feedstocks with oil contents below $20 \%$ in the described gasification process is likely to represent scenarios where large parts of the algae oil were previously extracted for other purposes (e.g. production of biodiesel). Therefore, proper LCA of the GHG emissions in such cases should carefully allocate the upstream emissions, such as those associated with the use of fertilizers, to all products (e.g. biodiesel and syngas) that are derived from the raw biomass. However, the basis for such allocation is itself somewhat arbitrary; e.g. economic values, weight fractions, heating values, etc. In order to avoid these complexities, the analysis of the GHG emission of syngas obtained from algae feedstock containing less than $20 \mathrm{wt} \%$ oil was not considered in the LCA section.

It was assumed that $80 \%$ of the produced ammonia was recycled back to the algae cultivation pond to reduce the consumption of nitrogen fertiliser. However, the energy consumption for the separation of ammonia from syngas was not considered in this study. Apart from the use of syngas within the gasification plant as an auxiliary fuel to the combustor reactor, a partial recycle of syngas was also considered to meet the heat and electricity demands of other parts of the biorefinery (e.g. dryer, pumps, centrifuge, etc.). To this end, it was assumed that the required amount of syngas is fed to a combined heat and power (CHP) unit to generate heat and electricity at an overall efficiency of $85 \%$.

According to the Intergovernmental Panel for Climate Change (IPCC, $4^{\text {th }}$ assessment report) the global warming potential (GWP) factors of 25 and 298 were used to calculate the $\mathrm{CO}_{2}$-equivalent emissions of methane and nitrous oxide over a 100 years time period, respectively ${ }^{23}$.

\section{Results and discussion}

In this section, the results obtained from the simulation and life cycle assessment of the described algae gasification process are presented. We first discuss the baseline scenarios 


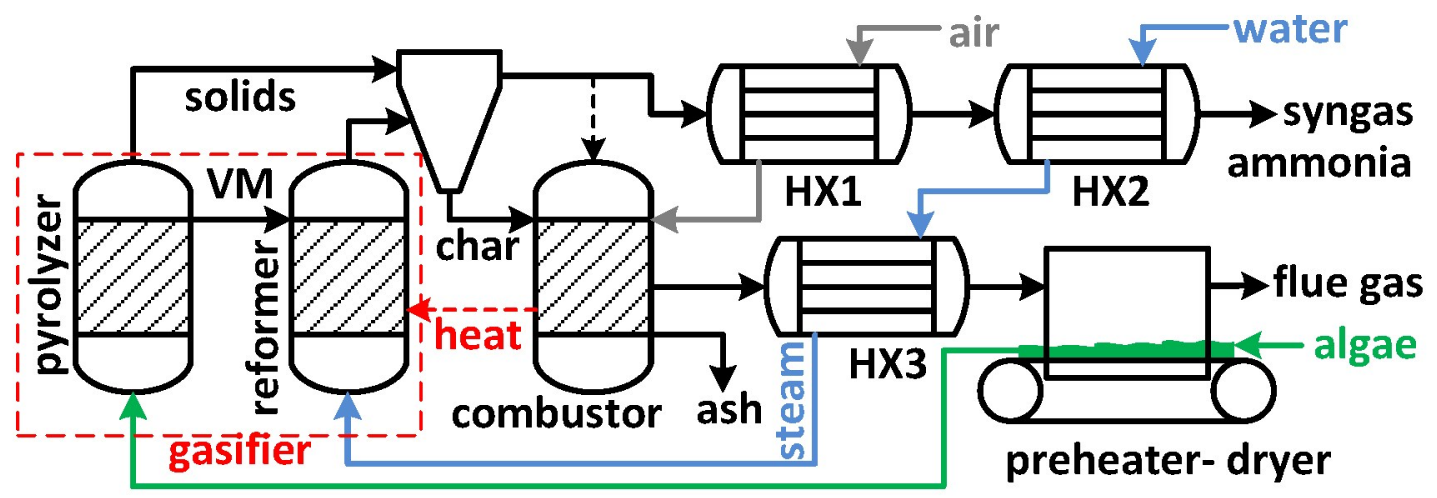

Fig. 2 Schematic process flow diagram of the algae gasification process. The dashed line to the combustor shows auxiliary syngas fuel to generate more heat if needed and the dashed line from the combustor to the reformer represents energy transfer between the two reactors via the circulation of the bed material.

Table 1 Design specs, set points, and parameter estimation subroutines within the process model.

\begin{tabular}{ll}
\hline Unit operation & Comment \\
\hline Pyrolyzer & Splits the feed into char and volatile fractions \\
Reformer & Allowable products: $\mathrm{H}_{2}, \mathrm{CO}, \mathrm{CO}_{2}, \mathrm{CH}_{4}, \mathrm{H}_{2} \mathrm{O}, \mathrm{H}_{2} \mathrm{~S}, \mathrm{NH}_{3}, \mathrm{P}$ \\
Syngas recycle & Axillary fuel to the combustor to meet the heat demands of the reformer \\
Combustor & $T_{c}=T_{r}+150^{\circ} \mathrm{C}$, Allowable products: $\mathrm{CO}_{2}, \mathrm{O}_{2}, \mathrm{~N}_{2}, \mathrm{H}_{2} \mathrm{O}, \mathrm{NO}_{2}, \mathrm{SO}_{2}, \mathrm{P}$ \\
Air flow rate & Calculated based on char and syngas flow rates to the combustor \\
HX1 & $50^{\circ} \mathrm{C}$ temperature approach at the air outlet side \\
HX2 & Syngas outlet $T: 120^{\circ} \mathrm{C}$, water inlet $T: 20^{\circ} \mathrm{C}$ \\
HX3 & $150^{\circ} \mathrm{C}$ Temperature approach at the steam outlet side \\
Feed preheater & Flue gas outlet $T: 120^{\circ} \mathrm{C}$, algae inlet $T: 20^{\circ} \mathrm{C}$ \\
\hline
\end{tabular}

Table 2 Ranges of parameters for global sensitivity analysis.

\begin{tabular}{lcccl}
\hline Parameter & $\begin{array}{c}\text { Nominal } \\
\text { Value }\end{array}$ & $\begin{array}{c}\text { Lower } \\
\text { bound }\end{array}$ & $\begin{array}{c}\text { Upper } \\
\text { bound }\end{array}$ & Unit \\
\hline Algae oil content & - & 0 & 40 & $\mathrm{wt} \%$ dry \\
Gasifier temperature & 800 & 700 & 900 & ${ }^{\circ} \mathrm{C}$ \\
Feed water content & 30 & 20 & 50 & $\mathrm{wt} \%$ \\
Steam to biomass ratio & 0.6 & 0.4 & 0.8 & $\mathrm{~kg} / \mathrm{kg}_{\text {algae }}$ \\
Fuel-air equivalence ratio & 0.20 & 0.10 & 0.25 & - \\
\hline
\end{tabular}

Table 3 Elemental compositions and lower heating values of algae fractions ${ }^{4}$.

\begin{tabular}{llc}
\hline Fraction & Elemental composition & LHV $(\mathbf{M J} / \mathbf{k g})$ \\
\hline Lipid & $\mathrm{C}_{1} \mathrm{H}_{1.83} \mathrm{O}_{0.17} \mathrm{~N}_{0.0031} \mathrm{P}_{0.006}$ & 36.3 \\
Protein & $\mathrm{C}_{1} \mathrm{H}_{1.56} \mathrm{O}_{0.3} \mathrm{~N}_{0.26} \mathrm{~S}_{0.006}$ & 23.9 \\
Carbohydrate & $\mathrm{C}_{1} \mathrm{H}_{1.67} \mathrm{O}_{0.83}$ & 17.3 \\
Nucleic acids & $\mathrm{C}_{1} \mathrm{H}_{1.23} \mathrm{O}_{0.74} \mathrm{~N}_{0.40} \mathrm{P}_{0.11}$ & 14.8 \\
\hline
\end{tabular}


Table 4 Elemental compositions and lower heating values of the algae feedstocks considered in the simulations. All values are on a dry basis.

\begin{tabular}{cccccc}
\hline $\begin{array}{c}\text { Oil } \\
(\mathbf{w t} \%)\end{array}$ & $\begin{array}{c}\text { Protein } \\
(\mathbf{w t} \%)\end{array}$ & $\begin{array}{c}\text { Carbohydrates } \\
(\mathbf{w t} \%)\end{array}$ & $\begin{array}{c}\text { Nucleic acid } \\
(\mathbf{w t} \%)\end{array}$ & Elemental composition & $\begin{array}{c}\text { LHV } \\
(\mathbf{M J} / \mathbf{k g})\end{array}$ \\
\hline 0 & 60 & 30 & 10 & $\mathrm{C}_{1} \mathrm{H}_{1.58} \mathrm{O}_{0.49} \mathrm{~N}_{0.19} \mathrm{P}_{0.006} \mathrm{~S}_{0.004}$ & 20.1 \\
20 & 49 & 25 & 6 & $\mathrm{C}_{1} \mathrm{H}_{1.63} \mathrm{O}_{0.43} \mathrm{~N}_{0.15} \mathrm{P}_{0.007} \mathrm{~S}_{0.003}$ & 23.9 \\
30 & 43 & 22 & 5 & $\mathrm{C}_{1} \mathrm{H}_{1.65} \mathrm{O}_{0.40} \mathrm{~N}_{0.13} \mathrm{P}_{0.007} \mathrm{~S}_{0.003}$ & 25.5 \\
40 & 37 & 20 & 3 & $\mathrm{C}_{1} \mathrm{H}_{1.67} \mathrm{O}_{0.37} \mathrm{~N}_{0.12} \mathrm{P}_{0.008} \mathrm{~S}_{0.003}$ & 27.4 \\
\hline
\end{tabular}

where the input parameters, except for the algae composition, are set to their nominal values given in Table 2. Then, using global sensitivity analysis, the influence of the primary input parameters on the process efficiency and gas yields are determined. Finally, the simulation results, in conjunction with our previous life cycle analysis of algae production in open ponds ${ }^{12}$, are used to estimate the life cycle GHG emission of the algae-derived syngas. The GHG emission values of algal syngas produced under different scenarios are subsequently benchmarked against the GHG emission of fossil-derived syngas to evaluate the potential for algal syngas to mitigate the carbon intensity of the syngas-based products.

It is also emphasized that the analysis presented in subsections Base Case Scenarios (section 3.1) and Sensitivity Analysis (section 3.2) are solely based on the product yields obtained in the gasification process, whereas the values reported in the Life Cycle Analysis (section 3.3) have been adjusted to account for the recycling of ammonia to the algae cultivation pond and for the partial consumption of syngas to supply energy to the entire algal biorefinery.

\subsection{Base Case Scenarios}

The results of simulations performed at the nominal values of the process parameters given in Table 2 for different algae compositions are listed in Table 5. Simulation results indicated that the hydrogen and carbon monoxide yields are linearly proportional to the oil content of the algae feedstock. The yields of hydrogen and carbon monoxide increased from 85 to $123 \mathrm{~g} / \mathrm{kg}_{\text {algae }}$ and from 485 to $707 \mathrm{~g} / \mathrm{kg}_{\text {algae }}$, respectively, by increasing the algae oil content from 0 to $40 \mathrm{wt} \%$. Also, the yields of carbon dioxide and ammonia slightly decreased at higher algae oil percentages. As expected, the yield of methane was fairly small (i.e. $\sim 1.0 \mathrm{~g} / \mathrm{kg}_{\text {algae }}$ ) at the operating conditions investigated here. Moreover, the $\mathrm{H}_{2}: \mathrm{CO}$ ratios in the syngas remained around 2.45 regardless of the algae composition (Figure 3a). As such, the LHV of syngas per unit mass of algae was linearly proportional to the oil content of the feedstock (Figure 3b), ranging from 15.3 to $22.1 \mathrm{MJ} / \mathrm{kg}_{\text {algae }}$. It is also worth mentioning that each of the heating values presented in this figure approximately equals to $80 \%$ of the LHV of its respective feedstock. Due to the decrease in the yield of carbon dioxide, the energy content per unit mass of the produced syngas itself also slightly increased with increasing the algae oil (Figure 3b) .

\subsection{Sensitivity Analysis}

The effect of the key input parameters on five model outputs, namely syngas LHV, CGE, $\mathrm{H}_{2}: \mathrm{CO}$ ratio, and $\mathrm{H}_{2}$ and $\mathrm{CH}_{4}$ yields were studied via global sensitivity analysis explained in section 2.2. After determining and ranking the influence of the input parameters on each model output, it is shown how each output would change by varying the two most influential input parameters over their considered ranges given in Table 2 while other parameters are kept at the mean values of their ranges.

Based on the results presented in Figure 4, the syngas LHV has an extremely high sensitivity to the algae oil content. In fact, as previously outlined in Table 4, the energy content of an algae feedstock is predominantly governed by its percentage of oil and therefore, it was expected to observe such a large impact from this parameter on the energy content of the products. Simulation results indicated that increasing the oil content from 0 to $40 \mathrm{wt} \%$ would increase the LHV of the produced syngas from 14 to $23 \mathrm{MJ} / \mathrm{kg}_{\text {feed }}$. We emphasize again that the values of syngas heating content were calculated based on the yields of hydrogen, carbon monoxide, and methane exiting the second heat exchanger $(H X 2)$. In other words, the energy contents of ammonia and that of the syngas consumed as an auxiliary fuel to the combustor were not considered.

The sensitivity analysis revealed that the overall energy efficiency of the algae gasification process as represented by CGE typically lies between 80 to $90 \%$. In contrast to the syngas LHV, the CGE was primarily dependent on the water content of the feedstock and the amount of steam supplied to the gasifier, with only a minor influence from the algae composition (Figure 5). The strong effect of feed water content and steam-to-carbon ratio on the cold gas efficiency suggests that these parameters should be optimized simultaneously in order to achieve the highest possible process efficiency.

The results of global sensitivity analysis and the effect of the two most influential parameters on the hydrogen yield are presented in Figure 6. As can be seen from this figure, the hy- 
Table 5 Simulation results for the base case scenarios (see the nominal values given in Table 2). All values are based on $1 \mathrm{~kg}$ of dry algae.

\begin{tabular}{ccccccc}
\hline \multirow{2}{*}{$\begin{array}{c}\text { Oil content } \\
\text { (wt\%) }\end{array}$} & \multicolumn{4}{c}{ Final products (g/kg algae) } & \multirow{2}{*}{$\begin{array}{c}\text { Syngas recycled } \\
\text { to combustor }\end{array}$} \\
\cline { 2 - 6 } & $\mathbf{H}_{\mathbf{2}}$ & $\mathbf{C O}$ & $\mathbf{C H}_{\mathbf{4}}$ & $\mathbf{C O}_{\mathbf{2}}$ & $\mathbf{N H}_{\mathbf{3}}$ & \\
\hline 0 & 85 & 485 & 0.4 & 544 & 117 & $9.7 \%$ \\
20 & 107 & 610 & 0.8 & 549 & 109 & $1.6 \%$ \\
30 & 116 & 665 & 1.0 & 533 & 101 & $0.1 \%$ \\
40 & 123 & 707 & 1.3 & 511 & 91 & - \\
\hline
\end{tabular}

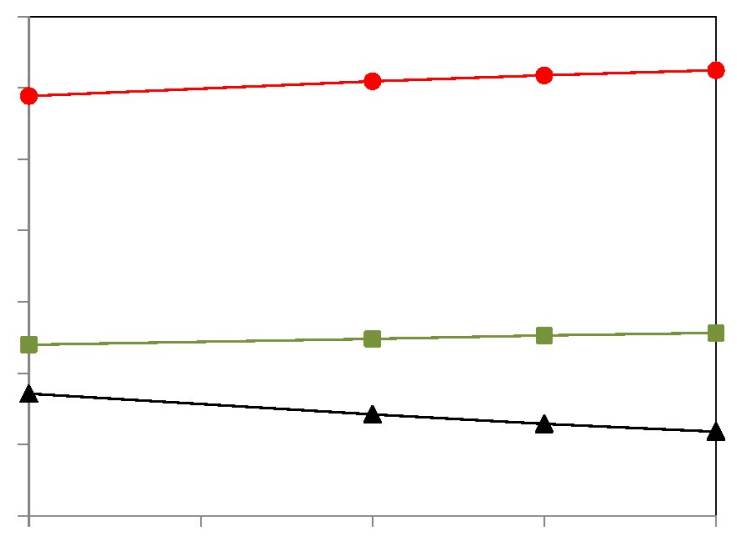

(a) Syngas composition

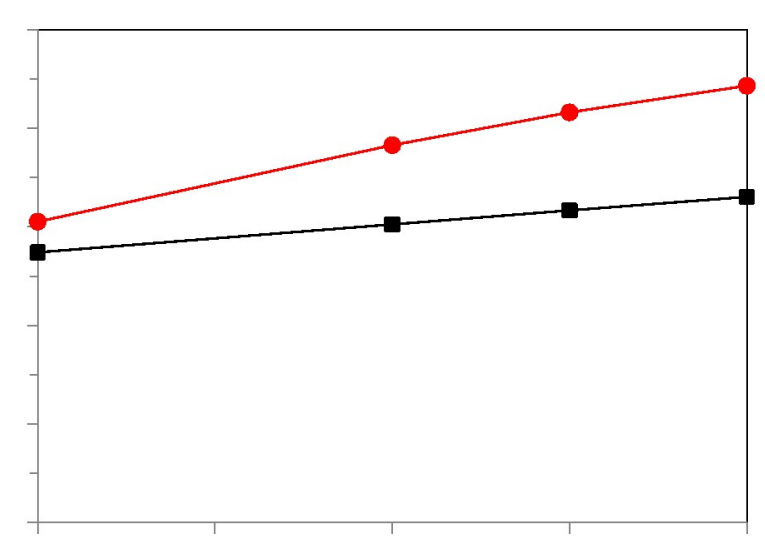

(b) Syngas LHV

Fig. 3 Syngas composition in terms of volume percentage (a) and lower heating value (b) vs. algae oil content (wt $\%$ dry basis). All other parameters are at their nominal values given in Table 2

drogen yield is almost entirely dependent on the oil content of the feedstock with a little influence from feed moisture when the algae feedstocks has a high oil content. Finally, the composition of the algae-derived syngas, represented by the $\mathrm{H}_{2}$ :CO ratio, was found to be largely controlled by feed water content and gasification temperature (Figure 7). As expected, $\mathrm{H}_{2}: \mathrm{CO}$ ratio increased when the operating conditions favored the forward water-gas-shift reaction - i.e. high vapor pressure and low temperature.

\subsection{Life Cycle Analysis}

As described in the methodology section, three scenarios for the drying of the algae slurry were evaluated: use of a conventional biomass belt dryer (route 1), use of solar energy to increase the solid content to $30 \mathrm{wt} \%$ before using the conventional belt dryer (route 2), and use of solar energy to increase the solid content to $70 \mathrm{wt} \%$ (route 3 ). An overview of these algae conversion pathways considered in this study and their corresponding net syngas production yields are shown in Figure 8. In all three cases, the solid content of the feed after dewatering and at the input to the gasifier were fixed at 20 and
$70 \mathrm{wt} \%$, respectively. We note that the net syngas yields presented here are based upon the nominal values of the key input parameters given in Table 2 after accounting for the partial consumption of the syngas to meet the heat and power demand of the entire biorefinery (dashed lines in Figures 2 and 8a).

As can be seen in Figure $8 \mathrm{~b}$, the drying process has a substantial impact on the net syngas yield. For an algae strain with $30 \mathrm{wt} \%$ oil content the amount of syngas produced from one kilogram of dry feedstock increases from 3.5 to $11.0 \mathrm{MJ} / \mathrm{kg}_{\text {algae }}$ just by utilizing solar energy to increase the solid content of the algae slurry from 20 to $30 \mathrm{wt} \%$. Likewise, a substantial gain in the net syngas yield can be obtained if the whole drying is carried out using solar energy -i.e. the net syngas yield in this case would increase to $19.6 \mathrm{MJ} / \mathrm{kg}$ algae. Regardless of the conversion route, a $1.5 \mathrm{MJ} / \mathrm{kg}_{\text {algae }}$ rise in the net yield of syngas is observed for every $10 \mathrm{wt} \%$ increase in the feedstock oil content.

In order to determine the carbon footprint of biofuels, one has to add up all the direct and indirect emissions associated with every step of the biomass cultivation, harvesting, and conversion. As far as algae-derived syngas is concerned, the 


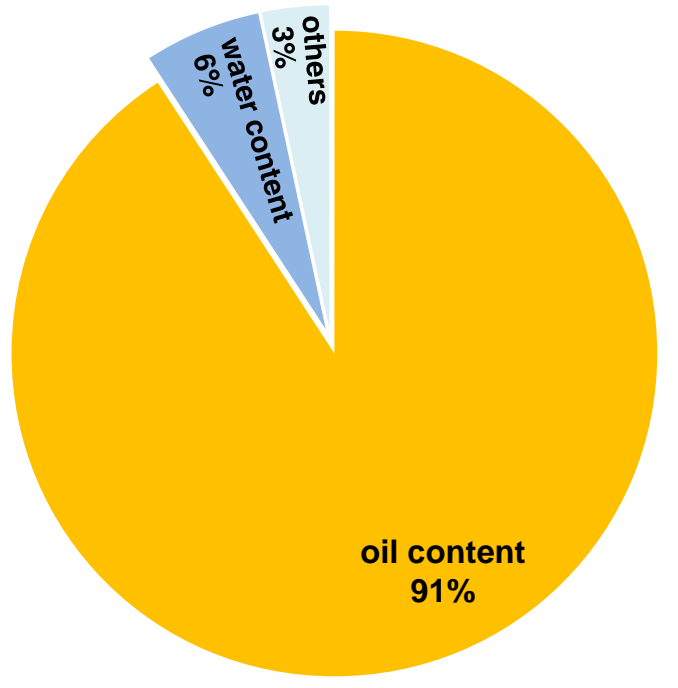

(a) Syngas LHV global sensitivity analysis

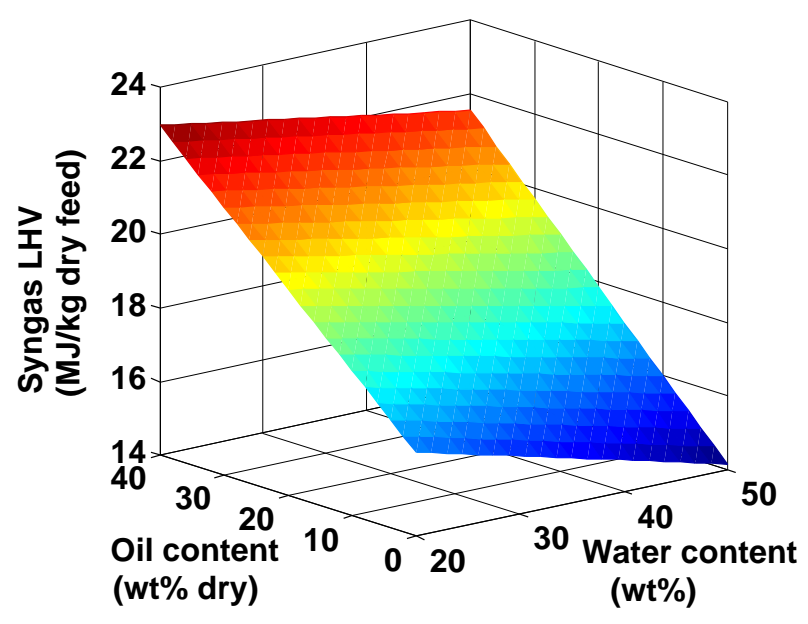

(b) Syngas LHV

Fig. 4 Global sensitivity analysis (a) and effects of the two most influencing parameters (b) for syngas LHV per kilogram dry feed.

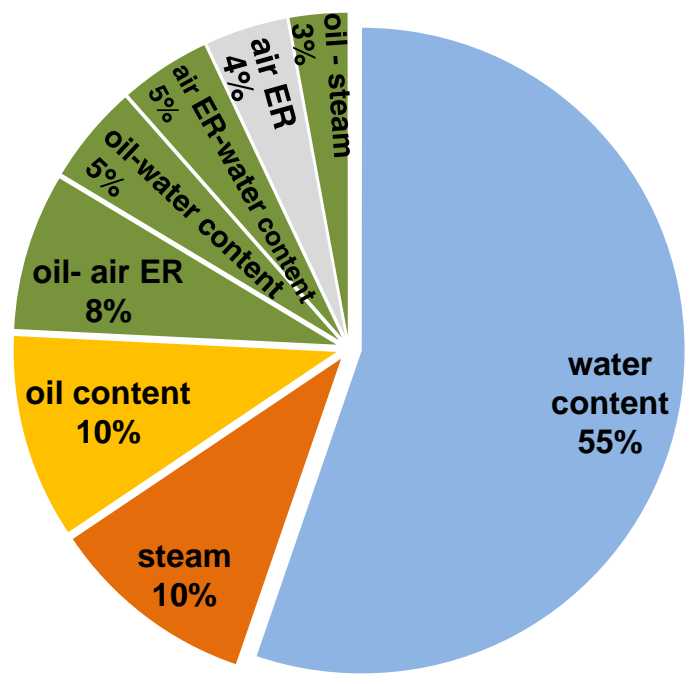

(a) CGE global sensitivity analysis

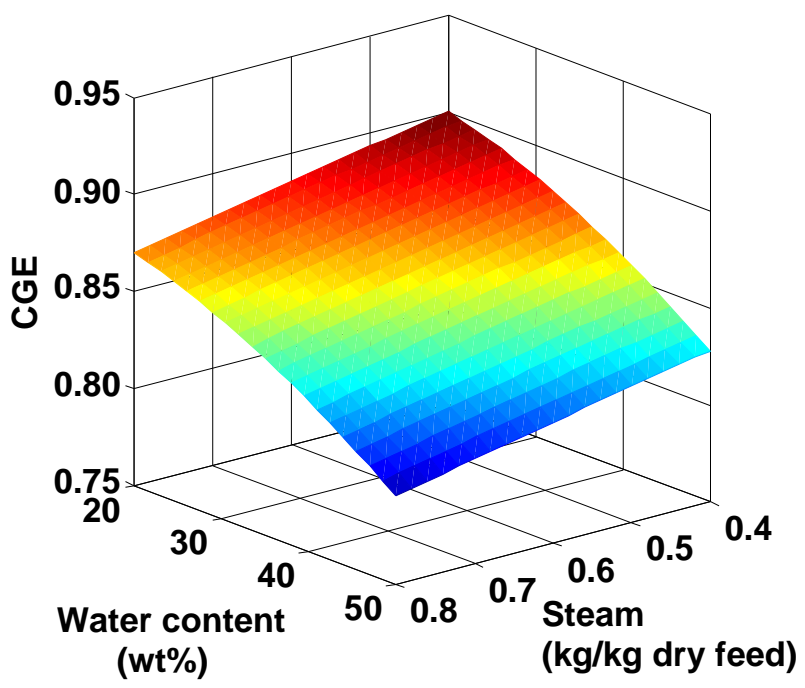

(b) CGE

Fig. 5 Global sensitivity analysis (a) and effects of the two most influencing parameters (b) for cold gas efficiency (CGE).

environmental stressors primarily belong to one of the following groups: electricity, heat, fertiliser, and plant construction. As shown in the previous LCA studies ${ }^{12,13}$, the carbon footprint of algal biofuels are heavily affected by the carbon intensities associated with the electricity and heat provided to the biorefinery. However, it is possible to suppress or eliminate this dependency through the use of solar energy or combustion of algae-derived products such as syngas and biogas.
In the present study, the external heat and electricity demand of the algal biorefinery is assumed to be fully provided by a combined heat and power (CHP) unit fed with algae-derived syngas produced on-site. As such, the emissions due to heat and electricity were eliminated and the net syngas production yields were adjusted accordingly.

Figure 9 shows the GHG emissions of the algae-derived syngas produced through different conversion strategies, as 


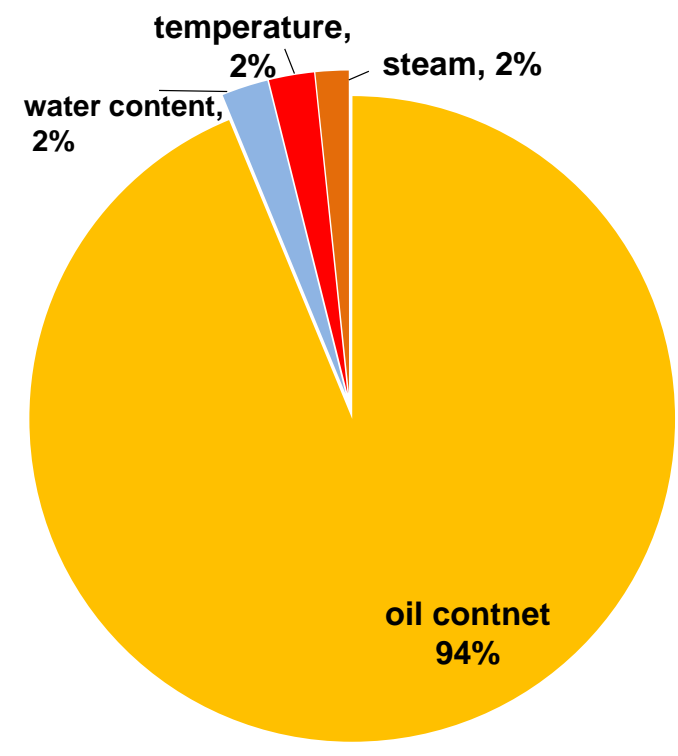

(a) $\mathrm{H}_{2}$ global sensitivity analysis

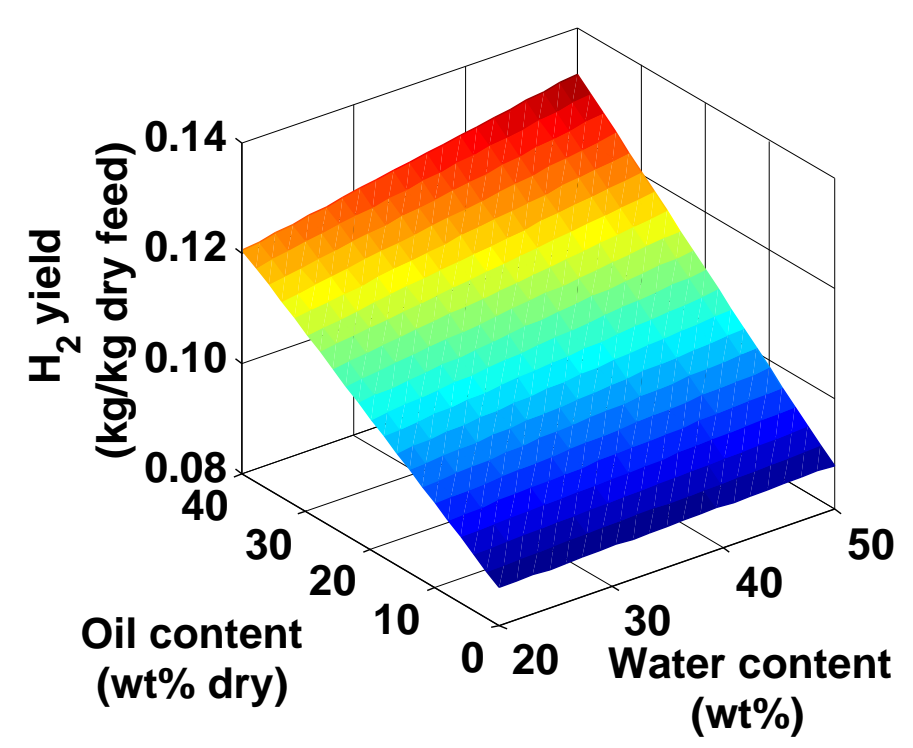

(b) $\mathrm{H}_{2}$ yield

Fig. 6 Global sensitivity analysis (a) and effects of the two most influencing parameters (b) for hydrogen yield per kilogram dry feed.

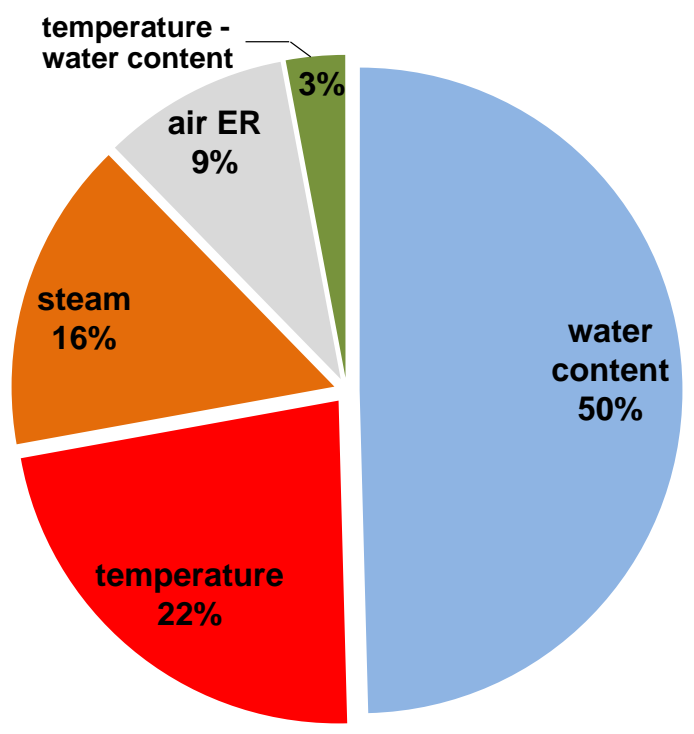

(a) Global sensitivity analysis for $\mathrm{H}_{2}: \mathrm{CO}$ ratio

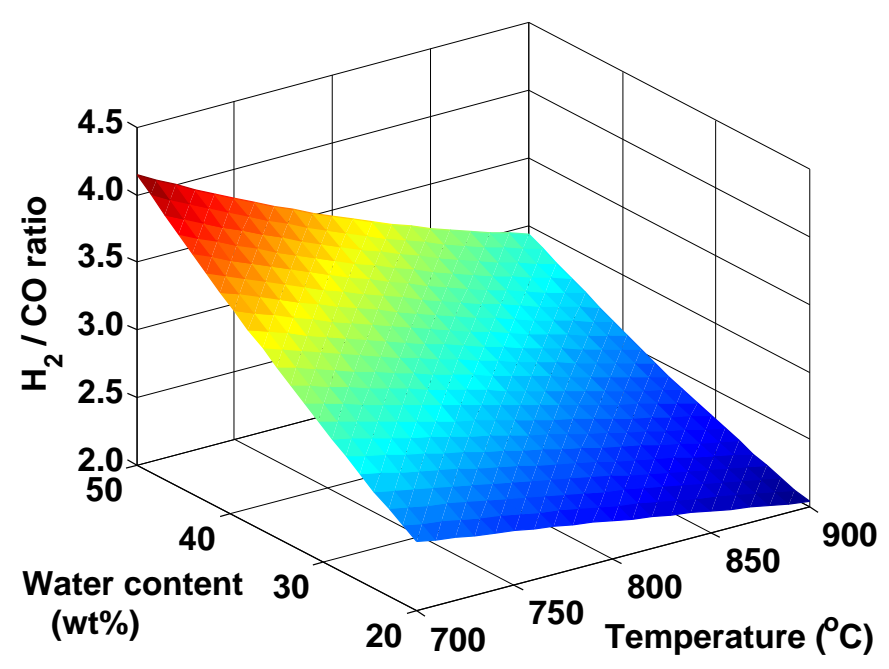

(b) $\mathrm{H}_{2}: \mathrm{CO}$ ratio

Fig. 7 Global sensitivity analysis (a) and effects of the two most influencing parameters (b) for $\mathrm{H}_{2}: \mathrm{CO}$ molar ratio.

explained in Figure 8a. These values are obtained by normalizing the total emission in each case by the net syngas yields provided in Figure 8b. For comparison, the corresponding GHG emission for the syngas derived from steam reforming of natural gas $^{24}$ is also added to Figure 9.

As can be seen, the life cyle emissions of algal syngas from route 1 are greatest among the scenarios considered here and are, in fact, likely to be comparable or higher than those of the natural gas-derived syngas. LCA also revealed that the algae oil content has a profound effect on the carbon footprint of algal syngas if the entire heat and electricity demand of the biorefinery is supplied through the combustion of syngas (route 1). The effect of algae composition on the life cycle emissions of algal syngas is negligible upon the utilization of 
solar dryers. For the range of algae oil content studied, the life cycle GHG emissions of algal syngas vary over a range of 27 to $38 \mathrm{~g} \mathrm{CO}_{2} / \mathrm{MJ}$, and 16 to $20 \mathrm{~g} \mathrm{CO}_{2} / \mathrm{MJ}$ for the routes 2 and 3 , respectively. Therefore, a gasification process that utilizes solar-assisted drying holds promise to bring significant emissions savings, particularly if higher solid concentrations can be obtained from the solar drying process. Another implication of these results would be that, if solar drying is to be used to reduce the solid content of the algae slurry, optimization of other growth and economic factors such as biomass annual productivity and fertiliser demand should be given a higher priority than the optimization of the oil content.

We note that the breakdown values for the emissions associated with the production of fertiliser are obtained by deducing the ammonia recovery credits from their respective gross values. Also, it should be realised that the upstream GHG emissions of natural gas-derived syngas includes the carbon footprint associated with extraction, transportation, and refining processes for the natural gas, while the steam reforming GHG emissions refers to the sum of the consumed natural gas as a feedstock to the process and as a fuel to supply the heat of reaction.

\section{Conclusions}

The production of algae-derived syngas in dual fluidized bed (DFB) gasifiers was simulated using Aspen Plus ${ }^{\circledR}$. It was found that, under the base case conditions set in the simulations, increasing the oil content of the feedstock from 0 to 40 wt\% would increase the LHV of the produced syngas from 15.3 to $22.1 \mathrm{MJ} / \mathrm{kg}_{\text {algae }}$ while it had a negligible effect on the $\mathrm{H}_{2}$ :CO ratio. Using a global sensitivity analysis, we determined the effect of each input parameter on the syngas LHV, cold gas efficiency, and product yields. The CGE of the process varies over a range of 75 to $90 \%$ and is primarily dependent on the feedstock water content and steam-to-biomass ratio. The life cycle analysis revealed that, if the carbon intensity of the drying step is reduced through the use of solar energy, the carbon footprint of algae-derived syngas (i.e. $<40$ $\mathrm{g} \mathrm{CO}_{2} / \mathrm{MJ}$ ) would compare favorably with that of syngas from fossil resources (i.e. $\sim 100 \mathrm{~g} \mathrm{CO}_{2} / \mathrm{MJ}$ ).

\section{Acknowledgements}

Part of this work was funded by the Technology Strategy Board (TSB) grant programme, "Carbon Abatement Technologies, Phase 2 competition for collaborative R\&D and feasibility”, Grant No. TS/J004553. The Technology Strategy Board is an executive body established by the United Kingdom Government to drive innovation. It promotes and invests in research, development and the exploitation of science, tech- nology and new ideas for the benefit of business, increasing sustainable economic growth in the UK and improving quality of life. MK acknowledges support by the Singapore National Research Foundation under its Campus for Research Excellence And Technological Enterprise (CREATE) program.

\section{References}

1 D. M. Alonso, J. Q. Bond and J. A. Dumesic, Green Chem., 2010, 12, 1493-1513.

2 P. Azadi, O. R. Inderwildi, R. Farnood and D. A. King, Renew. Sustain. Energy Rev., 2013, 21, 506-523.

3 B. Taylor, N. Xiao, J. Sikorski, M. Yong, T. Harris, T. Helme, A. Smallbone, A. Bhave and M. Kraft, Appl. Energy, 2013, 106, 262-274.

4 P. J. le B. Williams and L. M. L. Laurens, Energy Environ. Sci., 2010, 3, $554-590$.

5 I. K. Alghurabie, B. O. Hasan, B. Jackson, A. Kosminski and P. J. Ashman, Chem. Eng. Res. Des., 2013, 91, 1614-1624.

6 L. Sanchez-Silva, D. Lopez-Gonzalez, A. M. Garcia-Minguillan and J. L. Valverde, Bioresour. Technol., 2013, 130, 321-331.

7 K.-C. Yang, K.-T. Wu, M.-H. Hsieh, H.-T. Hsu, C.-S. Chen and H.-W. Chen, J. Taiwan Inst. Chem. Eng., 2013, 44, 1027-1033.

8 T. Minowa and S. Sawayama, Fuel, 1999, 78, 1213-1215.

9 D. C. Elliott, G. G. Neuenschwander, T. R. Hart, L. J. Rotness, A. H. Zacher, D. M. Santosa, C. Valkenburg, S. B. Jones and S. A. Tjokro Rahardjo, Pacific Northwest National Laboratory Richland, WA technical report, 2009.

10 P. Azadi and R. Farnood, Int. J. Hydrogen Energy, 2011, 36, 9529-9541.

11 P. Azadi, E. Afif, H. Foroughi, T. Dai, F. Azadi and R. Farnood, Appl. Catal. B Environ., 2013, 134-135, 265-273.

12 P. Azadi, G. Brownbridge, S. Mosbach, A. Smallbone, A. Bhave, O. Inderwildi and M. Kraft, Appl. Energy, 2014, 113, 1632-1644.

13 T. Shirvani, X. Yan, O. R. Inderwildi, P. P. Edwards and D. A. King, Energy Env. Sci, 2011, 4, 3773-3778.

14 L. Lardon, A. Hélias, B. Sialve, J.-P. Steyer and O. Bernard, Env. Sci. Technol., 2009, 43, 6475-6481.

15 R. Rauch, H. Hofbauer, K. Bosch, I. Siefert, C. Aichernig, H. Tremmel, K. Voigtlaender, R. Koch and R. Lehner, Proc. Second World Biomass Conf. Rome., 2004.

16 M. B. Nikoo and N. Mahinpey, Biomass Bioenergy, 2008, 32, 1245-1254.

17 W. Doherty, A. Reynolds and D. Kennedy, Biomass Bioenergy, 2009, 33, 1158-1167.

18 P. Spath, A. Aden, T. Eggeman, M. Ringer, B. Wallace and J. Jechura, National Renewable Energy Laboratory (NREL) technical report, 2005.

19 P. Azadi, J. Otomo, H. Hatano, Y. Oshima and R. Farnood, Int. J. Hydrogen Energy, 2010, 35, 3406-3414.

20 G. Brownbridge, P. Azadi, A. Smallbone, A. Bhave, B. Taylor and M. Kraft, Bioresour. Technol., 2014, 151, 166-173.

21 H. Rabitz and O. F. Aliş, J. Math. Chem., 1999, 25, 197-233.

22 M. Hassebrauck and G. Ermel, Water Sci. Technol., 1996, 33, 235-242.

23 S. Solomon, D. Qin, M. Manning, Z. Chen, M. Marquis, K. B. Averyt, M. Tignor and H. L. Miller, Intergovermental Panel on Climate Change (IPCC) technical report, 2007.

24 P. L. Spath and M. K. Mann, National Renewable Energy Laboratory (NREL) technical report, 2001. 


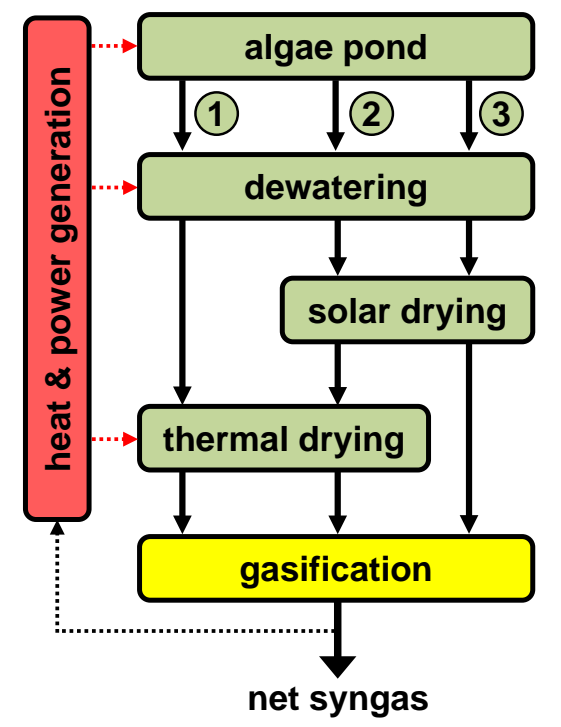

(a) Process flow diagram.

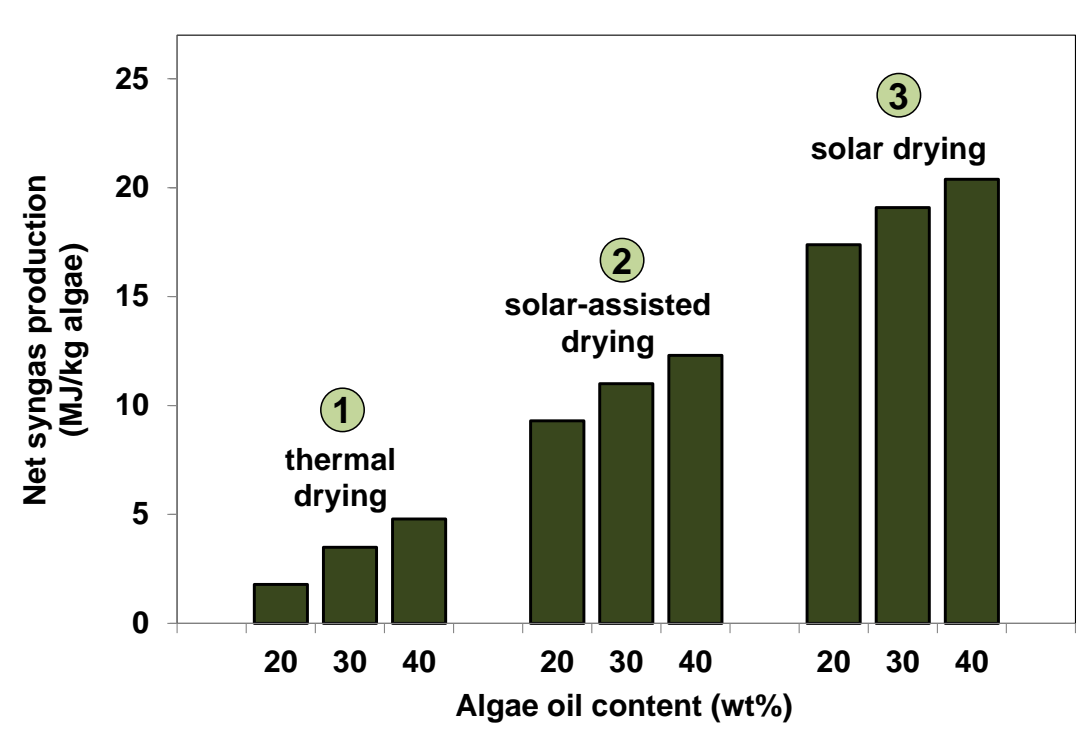

(b) Net syngas yield.

Fig. 8 Schematic process flow diagram of algae production and conversion considered in the life cycle assessment (a) and the net syngas yields obtained per kilogram of algae (b). All values are on a dry basis.

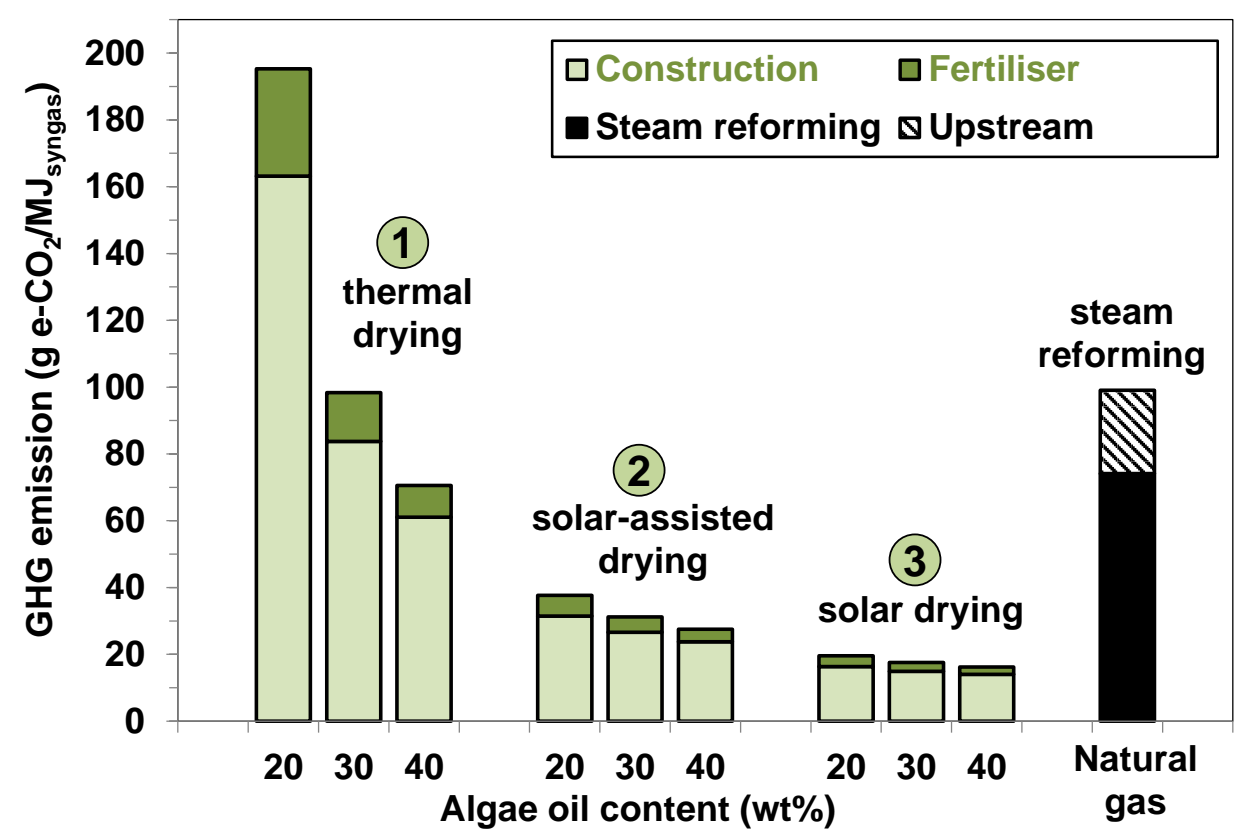

Fig. 9 Life cycle GHG emission of algae-derived syngas produced based on the strategies depicted in Figure 8. The carbon footprint of syngas production via steam reforming of natural gas ${ }^{24}$ is included for comparison. 